\title{
Experiencia y percepciones sobre el infográfico con fines educativos durante la formación docente
}

\author{
Experience and Perceptions About Infographic With Educational Purposes in Teaching Training
}

\section{Experiência e percepções sobre o infográfico para fins educacionais durante a formação de professores}

\begin{abstract}
Resumen:
Objetivo. Este artículo presenta los hallazgos de un estudio que busca conocer las percepciones de una docente y un grupo de alumnos y alumnas normalistas con respecto a dos experiencias de haber diseñado infográficos con fines educativos. Metodología. Este estudio fue de corte cualitativo. Para la recolección de información se implementó un grupo focal con cinco estudiantes de sexto semestre y una entrevista semiestructurada a la maestra de grupo que implementó la estrategia. Análisis de resultados. Los hallazgos sugieren una perspectiva positiva por parte de la maestra y el alumnado normalista respecto a la experiencia del diseño de infográficos, quienes declaran que contribuyó principalmente a la comprensión y organización de la información, especialmente facilitando la comprensión de textos académicos y disciplinares. Asimismo, las personas participantes concuerdan en que el diseño de infográficos facilita la organización de información relevante de forma visual, lo cual resulta innovador, creativo y de gran utilidad para el alumnado en formación inicial. Conclusiones y recomendaciones. Si bien es cierto es importante conocer las perspectivas de docentes y estudiantes sobre el uso de infográficos con fines educativos, se recomienda realizar
\end{abstract}


https://doi.org/10.15359/ree.26-1.23

https://www.revistas.una.ac.cr/index.php/educare

educare@una.ac.cr

estudios experimentales o cuasiexperimentales que constaten o refuten los hallazgos de este estudio y otros similares que se han abordado desde la perspectiva del personal docente y estudiantes.

Palabras claves: Infográficos; percepciones; normalista; formación docente; formación inicial.

\begin{abstract}
:
Objective. This article presents the findings of a study that seeks to know the perceptions of a teacher and a group of student teachers from a Normal Superior School related to two experiences designing infographics for educational purposes. Methodology. This study was qualitative. The data was collected by implementing a focus group conformed by five students in their sixth semester and an interview with the teacher who implemented the strategy. Results. The findings suggest a positive perspective from both the teacher and the students regarding the experience of designing infographics. They declare it mainly contributed to the comprehension and organization of information, specifically providing comprehension of academic and disciplinary texts. In addition, the participants state that the design of infographics facilitates the organization of relevant information in a visual way, which proves to be innovative, creative, and useful for students in initial education. Conclusions and recommendations. Even though it is important to inquire about teachers and students' perspectives on the use of infographics for educational purposes, it is recommended to conduct experimental or quasi-experimental studies which validate or refute the findings of this study and other similar studies which have been conducted from the perspectives of students and teachers.
\end{abstract}

Keywords: Infographics; perceptions; student teacher; teacher training; initial education.

\begin{abstract}
Resumo:
Objetivo. Este artigo apresenta os resultados de um estudo que procura conhecer as percepções de uma professora e de um grupo de estudantes de pedagogia sobre duas experiências de ter desenhado infográficos como estratégia educativa. Metodologia. Esta pesquisa foi qualitativa. Para a coleta de informações, foi implementado um grupo focal com cinco estudantes do sexto semestre e uma entrevista semiestruturada para a professora que implementou a estratégia. Análise dos resultados. Os resultados sugerem uma perspectiva positiva por parte da professora e dos estudantes de pedagogia sobre a experiência do desenho de infográficos. Declaram haver contribuido principalmente para a compreensão e organização da informação, facilitando especialmente a compreensão de textos acadêmicos e disciplinares. Da mesma forma, quem participou concorda que o desenho de infográficos facilita a organização visual de informações relevantes, inovadoras, criativas e muito úteis para estudantes iniciantes de pedagogia. Conclusões e recomendações. Embora seja necessaria a importância de conhecer as perspectivas de docentes e estudantes sobre o uso educativo de infográficos, recomenda-se a realização de estudos experimentais ou quaseexperimentais que confirmem ou refutem os resultados deste estudo e outros que, da mesma forma, foram abordados a partir da perspectiva de docentes e estudantes.
\end{abstract}

Palavras-chave: Infográficos; percepções; pedagogos; formação de professores; treinamento inicial.

\title{
Introducción
}

La importancia de desarrollar la comprensión lectora en el estudiantado recae en que es clave para acceder al aprendizaje y al conocimiento (Cassany et al., 2000; García Madruga et al., 1996; Solé, 1997), lo cual permite el desarrollo académico de los individuos. Específicamente en el nivel superior, no es de extrañar que la comprensión lectora del estudiantado es un tema

Selenne Ríos-Higuera, Isis Berenice Caro-Coronado y Rosa Ascención Espinoza-Cid

Los artículos de la Revista Electrónica Educare del Centro de Investigación y Docencia en Educación de la Universidad Nacional, Costa Rica, se comparten bajo términos de la Licencia Creative Commons: Reconocimiento, No Comercial, Sin Obra Derivada 3.0 Costa Rica. Las autorizaciones adicionales a las aquí delimitadas se pueden obtener en el correo: educare@una.cr 
https://doi.org/10.15359/ree.26-1.23

que ha sido investigado ampliamente, ya que esta habilidad juega un papel fundamental en la formación de profesionistas, pues es una actividad que habitualmente exige la mayoría del profesorado universitario (Echevarría Martínez y Gastón Barrenetxea, 2000). Sin embargo, los resultados arrojados no son favorables, pues apuntan a que no hay en el estudiantado una mejora significativa en la comprensión lectora conforme avanzan en su formación (Maldonado Fuentes et al., 2012). Por ello, es necesario que el personal docente encuentre diferentes estrategias y recursos que contribuyan a desarrollar en el estudiantado esta habilidad tan necesaria para desenvolverse en la vida académica y, más tarde, profesional. Es aquí donde la infografía puede tomar un papel relevante al utilizarse como un recurso o herramienta didáctica.

El uso de la infografía en Latinoamérica data de 1997, cuando fue incorporada a manuales de ciencias naturales en Argentina, y es resultado de la transformación de los recursos digitales durante el siglo XX (Palmucci, 2017). En referencia a investigaciones que se han realizado respecto al uso de infográficos en el ámbito de la educación, se encuentran aquellas como la de Minervini (2005) y la de Palmucci (2017), en las que se utilizaron infografías para procesar información obtenida de textos académico-científicos, y así poder acercar al estudiantado al nuevo conocimiento. Específicamente, Palmucci (2017) resalta la importancia que tiene la infografía como recurso en la enseñanza en temas científico-pedagógicos, ya que crea representaciones que integran fenómenos complejos, incorporando además recursos estéticos. En otras palabras, los infográficos pueden lograr hacer más óptimos y ágiles los procesos de comprensión, ya que reflejan "menor cantidad de texto escrito, precisando mayor información de manera gráfica, esto debido a que la imagen funciona como código universal, lo que exige menos trabajo mental que la lectura" (Aguirre et al., 2015, p. 26).

Similarmente, en los trabajos de Muñoz García (2014) y Rincón Carvajal (2016), además de proveer al estudiantado con nueva información enmarcada dentro de infografías claras y concisas, posteriormente los mismos aprendices elaboraron sus propios infográficos con el fin de hacer suyo el conocimiento. Rincón Carvajal (2016) extiende su proyecto de investigación para encontrar los beneficios que trae la utilización y elaboración de infográficos a la formación de docentes, argumentando que la retroalimentación, la indagación y la profundización en el proceso formativo de las futuras personas docentes se ven favorecidas con este recurso didáctico.

Debido a la importancia del desarrollo de la comprensión lectora y a la utilidad de los infográficos con fines educativos, se tuvo la experiencia de utilizar dicho recurso con una generación de estudiantes de una Normal Superior ubicada en un estado del noroeste de México, quienes se encontraban en proceso de formación para ser maestros y maestras de inglés. Los infográficos fueron realizados por el propio estudiantado como parte de actividades de poslectura en una de sus asignaturas; una experiencia fue cuando se encontraban en cuarto semestre y la otra cuando se encontraban en quinto. A pesar de que el personal docente que ha utilizado la infografía como recurso didáctico reconoce su utilidad para lograr aprendizajes, 
https://doi.org/10.15359/ree.26-1.23

https://www.revistas.una.ac.cr/index.php/educare

educare@una.ac.cr

resulta necesario indagar, desde la perspectiva del estudiantado normalista, sobre la experiencia de diseñar infografías en su proceso de formación docente como parte de las actividades de clase. De igual forma, es necesario conocer la perspectiva del personal docente que utiliza la infografía como estrategia didáctica para analizar los fortalezas y debilidades de su implementación, de tal forma que dicho análisis permita realizar mejoras al proceso de intervención utilizando este recurso. Para ello, se plantearon las siguientes preguntas:

- ¿Cuál es la percepción que tiene el estudiantado normalista acerca de haber diseñado infográficos con fines educativos durante su proceso de formación como docentes?

- ¿Cuál es la percepción que tiene el personal docente sobre la experiencia de haber implementado la infografía con fines educativos en sus clases?

En este trabajo se recogen los principales hallazgos en torno a las dos cuestiones planteadas. Por tanto, el objetivo general de este estudio fue determinar las percepciones con respecto al uso de infográficos con fines educativos. Se persiguieron dos objetivos específicos: 1) determinar la percepción del estudiantado normalista acerca de haber diseñado infográficos con fines educativos y 2) determinar la percepción del personal docente sobre la experiencia de haber implementado la infografía con fines educativos en sus clases.

\section{Desarrollo}

\section{¿Qué es la infografía?}

Un antecedente histórico de la infografía es el momento en el que el ser humano combina la imagen y la escritura por primera vez, siendo ejemplos de ello el Código de Hammurabi, los mensajes en los templos egipcios y dibujos en piedra o fragmentos de barro mesopotámico (Reinhardt, 2010). De hecho, de Pablos (1998) sostiene que, aunque no se ha catalogado como tal, la infografía (o infográfico) ha estado presente desde la época de las cavernas, lo cual indica que nació no como un producto de la informática, sino por el deseo de la especie humana de comunicarse (Reinhardt, 2010).

La infografía tal y como hoy la conocemos tiene sus orígenes en el periodismo (GuzmánCedillo et al., 2015) y es uno de los medios más importantes que los periódicos y revistas utilizan para transmitir la información de forma clara y precisa (Muñoz García, 2014). Diversos autores y autoras han definido la infografía y la consideran un género periodístico (Abreu Sojo, 2002). Entre las definiciones que recopila Abreu Sojo (2002), se observa que en su mayoría la definen como un recurso para presentar información compleja de una manera más visual y de fácil comprensión para el público lector. Es decir, la información se simplifica de tal forma que el lector y la lectora reciban menor cantidad de contenido textual con mayor significado y con ayuda de gráficos. Si bien es cierto la creatividad y la estética son elementos importantes al hacer una infografía, no debemos olvidar que el principal propósito no es entretener sino transmitir un mensaje (Damyanov y Tsankov, 2018).

4

Selenne Ríos-Higuera, Isis Berenice Caro-Coronado y Rosa Ascención Espinoza-Cid

Los artículos de la Revista Electrónica Educare del Centro de Investigación y Docencia en Educación de la Universidad Nacional, Costa Rica, se comparten bajo términos de la Licencia Creative Commons: Reconocimiento, № Comercial, Sin Obra Derivada 3.0 Costa Rica. Las autorizaciones adicionales a las aquí delimitadas se pueden obtener en el correo: educare@una.cr 


\section{La infografía con fines educativos}

El uso de la infografía en el ámbito educativo es reciente (Muñoz García, 2014). A partir de la revisión de algunos estudios, la infografía puede ser utilizada de dos formas principalmente: como estrategia de aprendizaje por medio de la cual el estudiantado elabora la infografía como evidencia de su comprensión sobre un tema (Guzmán-Cedillo et al., 2015; Muñoz García, 2014; Rincón Carvajal, 2016) o como estrategia de enseñanza por parte del personal docente, utilizándola como recurso para presentar la información al alumnado con el objetivo de transmitir el conocimiento (Minervini, 2005; Ponce et al., 2015; Reinhardt, 2010; Sudakov et al., 2016). En ambos casos, permite que el tema sea comprendido de una manera eficiente, incluso los temas complejos son presentados de una manera llamativa y atractiva (Aguirre et al., 2015). En otras palabras, se puede emplear para presentar al estudiantado la información de una manera atractiva o como una forma de desarrollar en el estudiantado habilidades para buscar, obtener y procesar información (desarrollo de la competencia digital y tratamiento de la información). En la experiencia docente que se reporta en este trabajo, fue precisamente esta última dinámica la que se utilizó; es decir, el estudiantado elaboró los infográficos a partir de información de carácter académico.

\section{Tipos de infografías}

Muñoz García (2014) menciona en uno de los puntos a considerar al diseñar una infografía que pueden ser de tipo informativo, cronológico, sobre relatos de hechos históricos, estadístico o mapas. Esta categorización está relacionada con el tipo de función que cumple, la cual, en el caso de la experiencia docente que aquí se reporta, fue informativa.

Por su parte, Damyanov y Tsankov (2018) señalan que los infográficos pueden ser de tres tipos: estáticos, interactivos y videoinfográficos. Según la definición de estos autores, las infografías de tipo estático son las más simples y comunes y, por lo general, contienen imágenes sin elementos animados. En cuanto al segundo tipo, los interactivos, contienen elementos animados; además, permiten la visualización de gran cantidad de información a primera vista. Finalmente, los videoinfográficos son una combinación de videos cortos con ilustraciones, imágenes y texto. Esta clasificación tiene que ver con el formato de presentación de la información. En esta experiencia docente se utilizó la infografía estática.

Independientemente de cuál sea el formato o el tipo de información incluida, las infografías contienen principalmente tres componentes: 1) elementos visuales, 2) elementos de contenido y 3) conocimiento (Damyanov y Tsankov, 2018). Por otra parte, en el ámbito educativo, las infografías didácticas se pueden clasificar por su tipología (Reinhardt, 2010):

1. Según las necesidades o características del usuario.

2. Según la estructuración de los contenidos.

3. Según el contexto o situación en la que se será utilizada. (p. 133) 
https://doi.org/10.15359/ree.26-1.23

https://www.revistas.una.ac.cr/index.php/educare

educare@una.ac.cr

Explica Reinhardt (2010) que las infografías que caen en la clasificación 1 se llevan a cabo según las necesidades de aprendizaje del individuo o grupo: su nivel de instrucción, su cultura y la etapa de desarrollo psicológico en la que se encuentre. En la clasificación 2, las infografías se estructuran según el tipo de aprendizaje que se quiera abordar; es decir, las características de la infografía quedarán determinadas por los procesos cognitivos que se desee promover en los educandos. Por último, señala Reinhardt (2010), la clasificación 3 se relaciona al tiempo y espacio de una situación de aprendizaje: un libro, una pantalla, dentro o fuera del aula, para una clase, para todo el ciclo escolar; puede ser individual o colectiva; de acuerdo al momento de la clase, puede utilizarse como disparador de un tema, como idea central, como aplicación de conocimientos o como generador de otros esquemas.

En relación con la infografía con fines didácticos, Muñoz García (2014) recomienda que se realice un minucioso diseño de la infografía antes de empezar con la parte técnica. Dicho diseño se lleva a cabo en cuatro fases. Primeramente, la autora recomienda plantear la temática; enseguida, recopilar datos para, posteriormente, estructurar la información de manera coherente y ordenada. Por último, Muñoz García (2014) recomienda realizar un esbozo. Una vez que estas fases se han completado, la autora sugiere utilizar herramientas gratuitas de software en línea para realizar los infográficos.

\section{La experiencia de realizar infográficos}

Las dos experiencias docentes en las cuales se implementó el uso del infográfico con fines educativos se llevaron a cabo en una Escuela Normal Superior en un estado del noroeste de México. El grupo de normalistas con quienes se tuvieron las dos experiencias en cuestión tenía un total de 19 estudiantes, de los cuales cuatro eran hombres y 15 eran mujeres de edades entre 20 y 23 años. Como ya se mencionó, el estudiantado realizó infográficos en cuarto y en quinto semestres como estrategia de poslectura. En cuarto semestre, los temas se centraron en contenidos vistos en la asignatura Planeación de la enseñanza y evaluación del aprendizaje, mientras que en quinto semestre, los temas eran relacionados a la materia de Observación y práctica docente III.

En cada uno de los semestres, el proceso de elaboración se conformó de tres fases. En la fase 1, se dieron las instrucciones para la elaboración de la infografía. En la fase 2, el estudiantado realizó los infográficos con el acompañamiento y monitoreo de la maestra que implementó la estrategia. En esta fase se aclararon dudas sobre la lectura y sobre la elaboración de los infográficos, y se hicieron correcciones a quienes así lo solicitaban.

Por último, en la fase 3 se compartieron las infografías por el grupo del WhatsApp de la clase, el cual mantuvieron en cuarto y quinto semestres para comunicarse en términos académicos con la maestra de esta intervención. Por ser una actividad de la clase, tanto en la 
experiencia en cuarto como en quinto semestre, la maestra evaluó los productos utilizando una lista de cotejo de elementos básicos como la calidad y cantidad de información, referencias, creatividad, formato (tamaño de letra, colores) y uso de imágenes (tablas 1 y 2). En total se produjeron nueve infografías: cinco fueron elaboradas en cuarto semestre (en el apéndice $A$ se muestran dos de ellas) y cuatro en quinto semestre (en el apéndice B se proporcionan dos ejemplos). En ambas experiencias, la maestra formó equipos de entre tres y cuatro integrantes para asignarles las lecturas a partir de las cuales debían elaborar los infográficos.

Tabla 1: Criterios de evaluación de infográficos en IV semestre

\begin{tabular}{lc}
\hline \multicolumn{1}{c}{ Criterios } & Puntos \\
\hline 1. La información acerca del ítem es suficiente. & 10 \\
2. La organización de la información (y de las imágenes, en su caso) es clara. & 10 \\
3. Las referencias están en estilo APA. & 10 \\
4. El diseño es atractivo. & 5 \\
5. La información está en inglés. & 5 \\
\hline Total & $\mathbf{4 0}$ \\
\hline
\end{tabular}

Nota: Elaboración propia.

Tabla 2: Criterios de evaluación de infográficos en $V$ semestre

\begin{tabular}{lc}
\hline \multicolumn{1}{c}{ Aspecto } & $\%$ \\
\hline Creatividad & 3 \\
Información contenida (calidad y cantidad) & 7 \\
Formato (que los colores estén claros, letra legible, fondo apropiado, etc.) & 6 \\
Referencias & 4 \\
\hline Total & 20 \\
\hline
\end{tabular}

Nota: Elaboración propia. 
https://doi.org/10.15359/ree.26-1.23

https://www.revistas.una.ac.cr/index.php/educare

educare@una.ac.cr

La dinámica de asignación de los textos a partir de los cuales se elaborarían las infografías fue diferente en cada semestre. En cuarto semestre, se trabajó el tema de los tipos de reactivos para exámenes de inglés. En sus equipos, el estudiantado debía buscar las fuentes de información, en internet principalmente, para realizar los infográficos; por tanto, tenían libertad de escoger las fuentes de su preferencia. Se observó que los textos que consultaron eran dirigidos principalmente a la comunidad docente; asimismo, contenían información corta y puntual y lenguaje formal pero no altamente especializado.

En quinto semestre, eran dos los temas con los que trabajaron para el diseño de los infográficos: la disciplina en el aula y la corrección de errores al trabajar la habilidad oral en inglés; ambos temas se relacionan con la enseñanza de dicho idioma. En esta ocasión, el estudiantado no tuvo oportunidad de escoger sus fuentes, pues la docente fue quien asignó los textos a partir de la bibliografía del curso. A diferencia de los del cuarto semestre, estos textos eran del área de enseñanza de lenguas, por lo que contenían mayor información que los utilizados en cuarto semestre. Además, el lenguaje era especializado y con mayor complejidad en términos de estructuración lingüística.

En términos generales, la realización de los infográficos se llevó a cabo en una secuencia muy similar a la que Muñoz García (2014) propone. Sin embargo, el diseño del producto utilizando las herramientas en línea se hizo desde el principio y no al final. En cuanto a valoración académica, las infografías producidas en ambas experiencias tuvieron un valor asignado dentro de la calificación en cada materia donde se realizaron. En relación a la evaluación, la maestra fue quien en ambos casos determinó los criterios para la misma.

\section{Enfoque, tipo de investigación y diseño}

Este estudio tuvo un enfoque cualitativo. Leavy (2017) lo define como el enfoque que valora la profundidad del significado así como las experiencias subjetivas de la gente. La autora añade que este enfoque se utiliza con frecuencia en investigación descriptiva, lo cual es el caso en el presente estudio. El objetivo de la investigación descriptiva es obtener descripciones robustas del evento, actividad o situación que se pretende estudiar, así como de individuos o grupos a partir de las perspectivas de la propia gente que lo experimenta (Leavy, 2017). Los estudios descriptivos recogen información sobre las variables o conceptos de interés pero sin llegar a establecer relaciones entre ellos (Hernández Sampieri et al., 2014). En relación a ello, el presente estudio se enfocó en determinar las perspectivas de estudiantes y una docente con respecto a la implementación de infográficos con fines educativos dentro de sus clases.

Por último, el diseño del estudio consistió en un estudio de caso. Si bien, según Creswell y Poth (2013), varios autores se refieren al estudio de caso como una estrategia o una metodología, el autor prefiere el segundo, especificando que es un tipo de diseño de investigación cualitativa por medio del cual se investiga un sistema (caso) de la vida real que está ocurriendo en ese 
momento. Más aún, Hernández Sampieri et al. (2014) consideran el estudio de caso como uno de los diseños básicos de la investigación cualitativa. Además, los autores enfatizan que por diseño en investigación cualitativa se refieren "al abordaje general que habremos de utilizar en el proceso de investigación" (Hernández Sampieri et al, 2014, p. 470), el cual puede sufrir modificaciones a lo largo del proceso desde la inmersión inicial hasta el análisis de los datos y la generación de la teoría.

\section{Población, muestra y contexto}

Se delimitó la población a estudiantes de sexto semestre de la licenciatura en Educación Secundaria con especialidad en Inglés que hubieran participado en la elaboración de infográficos con fines educativos en cuarto y en quinto semestre; este último era el semestre inmediato al vigente en el momento del estudio (sexto semestre). Una vez delimitada la población, se optó por una muestra no probabilística, a la cual también se le denomina "muestra dirigida" y cuya selección obedece a las características de la investigación y no a criterios estadísticos (Hernández Sampieri et al, 2014). Específicamente, dicha muestra fue de sujetos voluntarios (Hernández Sampieri et al., 2014).

El contexto en cual se llevó a cabo el estudio fue una Escuela Normal ubicada en una ciudad de un estado en el noroeste de México. Esta institución forma docentes para dar clases en escuelas públicas en nivel secundaria, es decir, a estudiantes de entre 11 y 15 años de edad. Al momento del estudio, la Escuela Normal mencionada ofrecía las especialidades de Inglés, Matemáticas y Formación Cívica y Ética.

\section{Técnicas de recolección y análisis de la información}

La información se recolectó cuando el alumnado se encontraba en sexto semestre. Para recabar los datos, se utilizó un enfoque cualitativo por medio de las técnicas de grupo focal y entrevista semiestructurada. Para implementar el grupo focal, se solicitaron voluntarios que quisieran participar. El grupo con el cual se tuvieron las dos experiencias docentes de implementación de infografías con fines educativos reunía un total de 19 estudiantes; sin embargo, al momento de recolectar la información dos habían desertado, por lo que quedaron 17, de los cuales 5 se presentaron como voluntarios para el grupo focal. Se utilizó como instrumento una serie de preguntas detonantes, para lo cual se llevó a cabo un proceso de validez de contenido por parte de dos docentes investigadores. La validez de contenido es el "grado en que un instrumento refleja un dominio específico de contenido de lo que se mide" (Hernández Sampieri et al., 2014, p. 201). Dichas preguntas eran sobre la opinión acerca de la experiencia de haber diseñado infográficos, la utilidad, frecuencia y circunstancias en las que los habían consultado con fines académicos o prácticos, y sugerencias respecto a utilizar infográficos en la enseñanza. 
https://doi.org/10.15359/ree.26-1.23

https://www.revistas.una.ac.cr/index.php/educare

educare@una.ac.cr

La entrevista semiestructurada se aplicó a la maestra que había implementado el uso de infográficos en el grupo. La guía de preguntas para la entrevista pasó por un proceso de validez de contenido por parte de los mismos docentes investigadores que validaron las preguntas detonantes para el grupo focal. Al momento de dicha implementación, la maestra tenía siete años de servir en la Escuela Normal como formadora de docentes; al momento de la entrevista, llevaba ya nueve años de servicio. Se utilizó como instrumento una guía de preguntas sobre la experiencia de utilizar infográficos con fines educativos, aspectos favorables y desfavorables obtenidos de esta experiencia, y recomendaciones en relación con el uso de infografías con fines educativos.

El análisis de la información obtenida tanto por medio de la técnica del grupo focal como de la entrevista semiestructurada se realizó con una perspectiva cualitativa y se llevó a cabo en un procesador de textos. Para ello, fue necesario leer varias veces la información recabada por medio del grupo focal y de la entrevista semiestructurada. Se procedió a realizar un proceso de codificación sugerido por Creswell (2007) y Tesch (1990) (citados en Creswell, 2012), para lo cual se siguieron los pasos que a continuación se enlistan: 1) lectura cuidadosa de todas las transcripciones, 2) identificación de segmentos de texto y asignación de código, 3) agrupación de códigos similares para reducir la lista de códigos y 4) obtención de categorías (temas).

Según Best y Kahn (2006), es común que en los estudios cualitativos se recurra a la triangulación para validar los hallazgos de manera interna. Según estos autores, dicho proceso consiste en verificar datos provenientes de otras fuentes, de investigadores diferentes o diversos procedimientos de recolección de datos con el fin de identificar concordancias. En el estudio presente, se procedió a triangular la información proveniente de dos fuentes diferentes: el estudiantado y la maestra del grupo.

Como resultado de este proceso, se obtuvieron las categorías 1) estrategia, 2) utilización y 3) sugerencias. En la primera categoría se identificaron cinco subcategorías: organización, comprensión, creatividad, innovación y utilidad. En la segunda categoría se identificaron como subcategorías fines académicos y fines profesionales. Por último, en la categoría 3 se identificaron las subcategorías de recurso didáctico, difusión y preparación.

Para fines de presentación de hallazgos, y a partir de lo expuesto por el alumnadoy la maestra, la información se organizó en cuatro temas. En este sentido, las subcategorías de la categoría 1 se agruparon en dos: un tema donde se exponen las perspectivas sobre el infográfico en relación con la comprensión lectora, y el otro tema en el cual se plasman las perspectivas del infográfico como un recurso innovador. En el resto de los temas, se presenta la información correspondiente a las subcategorías identificadas. Para el análisis de los hallazgos se utilizó la estrategia de triangulación de datos para identificar coincidencias e inconsistencias. Dicha estrategia consiste en utilizar diferentes fuentes o instrumentos de recolección de información (Hernández et al., 2014; Leavy, 2017) y contribuye a una mayor confianza en la presentación de los hallazgos (Leavy, 2017). En el caso de este estudio, la triangulación se efectuó a través de comparar datos provenientes de dos fuentes: el estudiantado y la maestra de grupo que implementó las infografías. 


\section{Hallazgos}

\section{La elaboración de infográficos como estrategia para comprender y organizar información}

Haber tenido la oportunidad de realizar infográficos fue una experiencia positiva para el estudiantado que participó en el grupo focal, según sus opiniones. En general, el alumnado dijo que esta experiencia les proporcionó la ventaja de organizar, resumir, repasar y comprender información.

era la manera que organizábamos nuestras ideas y quedaban plasmadas en una... de diferente manera. (Estudiante 5, comunicación personal, 11 de abril de 2019)

creo que es una estrategia que te ayuda a comprender mejor lo que leímos porque estás resumiendo toda la información y te puedes enfocar en los puntos principales. (Estudiante 4, comunicación personal, 11 de abril del 2019)

pues... yo pienso que te ayuda a resumir información y entender mejor el tema. (Estudiante 3, comunicación personal, 11 de abril de 2019)

puede servir como una actividad de repaso de algún tema importante e incluso puede servir como una estrategia de estudio para los alumnos porque tú captas lo más importante en ese infográfico. (Estudiante 1, comunicación personal, 11 de abril de 2019)

Coincidiendo con el estudiantado normalista, la maestra opinó que la elaboración de infográficos como estrategia de poslectura contribuye a desarrollar la comprensión lectora, en especial a identificar las ideas principales de un texto.

Yo creo que es bueno para los alumnos que elaboren los infográficos y no que se los dé yo elaborados, pues, siellos los hacen, deberán primero comprender el texto, en especialidentificar las ideas principales, para luego poder plasmarlas en la infografía. (Maestra, comunicación personal, 13 de abril del 2019)

Estas perspectivas coinciden con los hallazgos de Guzmán-Cedillo et al. (2015) en cuanto a que el estudiantado los consideró como una herramienta que facilita comprender la información.

\section{El infográfico: una estrategia creativa, innovadora y útil}

Una de las personas participantes afirmó que era algo diferente a lo que habían hecho hasta ese momento, además de señalar que lo consideraba creativo, lo cual fue secundado por otra de las personas participantes. 
https://doi.org/10.15359/ree.26-1.23

https://www.revistas.una.ac.cr/index.php/educare

educare@una.ac.cr

considero que es una estrategia muy creativa y era diferente a las demás que hacíamos. (Estudiante 5, comunicación personal, 11 de abril de 2019)

yo opino que es una manera creativa para poder organizar la información después de leer. (Estudiante 2, comunicación personal, 11 de abril de 2019).

Por su parte, la maestra coincidió en esta parte donde se afirma la innovación de utilizar el infográfico como recurso didáctico.

Me pareció que fue una buena experiencia, algo que no habian hecho los muchachos en las clases, según dijeron. (Maestra, comunicación personal, 13 de abril del 2019)

En cuanto a la utilidad que la elaboración de infográficos podía tener para el estudiantado, quienes participaron en el grupo focal coincidieron en que dicho recurso era de utilidad principalmente para la comprensión y asimilación de información.

en lo personal esa estrategia para mí fue útil dado que algunos temas que no comprendía, gracias a esos infográficos, tenía la información más importante, la información más... pues... relevante, y pues tomar lo más importante de cada uno para poder entender poco mejor lo que estaba viendo como tema. (Estudiante 1, comunicación personal, 11 de abril de 2019)

Por otro lado, también consideraron que la utilidad de los infográficos residía en su forma creativa e innovadora, la cual ayuda a obtener la atención de sus espectadores y renueva las estrategias empleadas por el personal docente.

es una manera creativa e innovadora para nuestra formación. Considero que es importante innovar sobre las estrategias que se utilizan para la formación docente. (Estudiante 2, comunicación personal, 11 de abril de 2019)

Además, la maestra comentó que elaborar infografías podía desencadenar en los estudiantes procesos cognitivos e, incluso, metacognitivos.

elaborar infografías es de mucha utilidad para los alumnos... Les ayuda a organizar sus ideas, a ponerse en el lugar de su posible audiencia, de tal forma que una serie de procesos cognitivos empiezan a llevarse a cabo en sus cabecitas. Incluso creo que pueden reflexionar sobre su propia capacidad lectora al hacer esto... sobre sus propias capacidades intelectuales, tal vez. (Maestra, comunicación personal, 13 de abril del 2019 


\section{Utilización de los infográficos con propósitos académicos y profesionales}

Para tener una idea general del uso de los infográficos por parte del alumnado, se les preguntó sobre las circunstancias en las que los habían consultado con fines académicos y profesionales. Según lo afirmaron, principalmente los utilizaron para sus prácticas en las escuelas secundarias, es decir, elaboraron infográficos para presentar información de la clase de inglés a sus estudiantes, pero nadie mencionó haber consultado los infográficos realizados en cuarto y quinto semestres con fines académicos. Sin embargo, sí dijeron consultar infográficos para aclarar dudas.

pues anteriormente mi equipo de investigación en el quinto y sexto semestre realizamos el uso de unos infográficos para explicar el uso del "was" y el "were" a tercer año de secundaria, y fue útil debido a que nosotros ya habíamos utilizado esta estrategia anteriormente para resumir información y a los alumnos les resultó más fácil para entender el pasado de algún verbo y cuándo se utilizaba. (Estudiante 2, comunicación personal, 11 de abril de 2019).

...en cuanto a la práctica, siento que es más fácil para los alumnos verlo de manera visual el tema porque así se puede ejemplificar y tienen más interés por el tema. (Estudiante 5, comunicación personal, 11 de abril de 2019)

Cuando tengo alguna duda o algo que no entiendo de un tema en específico trato de buscar imágenes donde tenga la información del tema que estoy buscando; normalmente lo hago para cuando tengo alguna duda para mis prácticas o cuando hay algún tema que no entiendo. (Estudiante 1, comunicación personal, 11 de abril de 2019).

Sin embargo, la maestra contradice lo afirmado por el estudiantado en el grupo focal, pues declaró que, a partir de sus observaciones y experiencia con el alumnado, este no había vuelto a consultar los infográficos diseñados.

A veces me preguntan cosas que ellos mismos plasmaron en sus infográficos. Incluso, una vez leí el diario de campo de una alumna y en sus reflexiones se cuestionaba sobre aspectos teóricos que había abordado en uno de los infográficos que se habían compartido en el grupo de WhatsApp realizados por ellos. Para mí, eso quiere decir que no los volvieron a consultar. (Maestra, comunicación personal, 13 de abril del 2019)

\section{Sugerencias para la utilización de infográficos con fines educativos}

En cuanto a sugerencias para mejorar la utilización de infográficos como recurso didáctico, el estudiantado indicó que sería bueno seguirlos utilizando para comprender y resumir información. 
https://doi.org/10.15359/ree.26-1.23

https://www.revistas.una.ac.cr/index.php/educare

educare@una.ac.cr

sugiero para la aplicación de esta estrategia ... elaborarlos más para hacerlos llamativos para no caer siempre en lo mismo del resumen de ideas, y cada uno encuentre el diseño que le guste más para que le llame más la atención. (Estudiante 4, comunicación personal, 11 de abril de 2019)

La maestra señaló a modo de sugerencia que sería útil difundir los infográficos entre la comunidad escolar.

Algo que creo me falló en esta experiencia fue darle... promover una mayor difusión. O sea, solamente los compartimos por WhatsApp. Después pensé que pudimos haberlos imprimido en pósters... o presentado de alguna forma a los demás alumnos y maestros. (Maestra, comunicación personal, 13 de abril del 2019)

Además, la maestra reconoce que no tenía suficiente información general respecto al diseño de infográficos.

... debí haberme informado más al respecto, o sea, en cuanto a cuestiones de diseño para aplicar la estrategia de una forma más planeada. (Maestra, comunicación personal, 13 de abril del 2019)

\section{Discusión y conclusiones}

Alyahya (2019) argumenta que el uso de infográficos para compartir información motiva al estudiantado, lo cual puede explicar en parte el optimismo de las personas participantes en este estudio, pues, de manera general, los hallazgos sugieren que el estudiantado que participó en esta experiencia áulica tiene una perspectiva positiva hacia el uso de los infográficos con fines educativos. Estas perspectivas coinciden con los hallazgos de Guzmán-Cedillo et al. (2015) y Alyahya (2019) en cuanto a que el estudiantado los consideró como una herramienta que facilita comprender la información. Un ejemplo claro serían las respuestas observadas del estudiantado, las cuales fueron optimistas en relación con el proceso general de elaboración de infográficos, y coinciden con los resultados del estudio de Alyahya (2019): arrojaron que el estudiantado se mostró entusiasta ante la oportunidad de representar información en visuales.

Además de estas perspectivas positivas por parte del estudiantado, la maestra que participó en el estudio también considera que la realización de infográficos favorece su comprensión y organización de la materia. Por su parte, Bicen y Beheshti (2017) también reportan un estudio cuantitativo cuyos resultados muestran que el estudiantado universitario tenía una percepción positiva acerca del uso de infográficos con fines educativos. Aunado a esto, Shabak Alrwele (2017) cita estudios que han demostrado que el uso de infográficos instruccionales mejora las competencias disciplinares del estudiantado, su creatividad y sus habilidades superiores del pensamiento (análisis, síntesis y pensamiento crítico). También cita un estudio en el que se 
https://doi.org/10.15359/ree.26-1.23

confirma el uso de infográficos para que el estudiantado demuestre su habilidad de comprender un tema y resumir las ideas principales.

Por otra parte, las personas participantes manifestaron a través de esta experiencia que habían llevado el uso de infográficos a la práctica profesional con su alumnado de secundaria, similar al estudio de Guzmán-Cedillo et al. (2015), quienes reportan el probable uso de la infografía por parte de las personas participantes más allá de la clase. Incluso, Shabak Alrwele (2017) pone de referencia estudios que muestran la efectividad del uso de infográficos para la enseñanza de la gramática del inglés como lengua extranjera.

Una de las debilidades señaladas por la maestra durante la implementación de los infográficos como estrategia de poslectura fue la falta de información con respecto al diseño. Como todo contenido por enseñar, es necesario que el personal docente primeramente se prepare y conozca toda la información posible al respecto, no solo con el fin de darla a conocer a sus alumnos, sino también de guiarlos durante todo el proceso, pues si bien es cierto el principal propósito de una infografía no es entretener sino transmitir un mensaje (Damyanov y Tsankov, 2018), no debemos olvidar que la representación visual juega un papel importante si queremos presentar información compleja de una manera digerible.

Además de lo anterior, la maestra señaló otra debilidad en el proceso: la falta de difusión. El personal docente debe verse como un contribuyente intelectual; una manera de reflejar esta imagen es promoviendo sus productos, especialmente en la actualidad, dado que la imagen del personal docente ha decaído. Aunado a esto, se debe sacar provecho de los diferentes medios de comunicación masiva, en especial si el propósito es académico o científico.

En conclusión, los hallazgos de este estudio reflejan perspectivas positivas hacia el uso del infográfico con fines educativos, tanto por parte del estudiantado como de la maestra que implementó la estrategia. Además, los hallazgos en el presente estudio sugieren que 1) las perspectivas de estudiantes y docente sobre el uso de infográficos en las clases (en este caso específico, el diseño por parte del estudiantado) es favorable, ya que consideran que mejora su habilidad para organizar y comprender información, y 2) el alumnado mostró entusiasmo al elaborarlos, lo cual coincide con hallazgos de otros estudios (Alyahya, 2019; Bicen y Beheshti, 2017; Guzmán-Cedillo et al., 2015; Shabak Alrwele, 2017). Como personas formadoras de docentes, es importante que apliquemos estrategias diversas que contribuyan a la comprensión de textos académico-científicos, ya que esto beneficia a los futuros educadores y educadoras no solo en su formación inicial sino también en su profesión una vez que se inserten en el mercado laboral.

Por último, indagar sobre las perspectivas de estudiantes y docentes en cuanto al uso de infográficos en el ámbito académico es importante. Sin embargo, consideramos que es necesario también comprobar sistemáticamente y en términos cuantitativos qué tanto contribuye al aprendizaje el uso de este recurso, por lo que se recomienda realizar estudios experimentales o cuasiexperimentales que constaten o refuten los hallazgos de los diferentes estudios, incluido este, abordados desde la perspectiva del personal docente o de estudiantes. 
https://doi.org/10.15359/ree.26-1.23

https://www.revistas.una.ac.cr/index.php/educare

educare@una.ac.cr

\section{Referencias}

Abreu Sojo, C. (2002). Periodismo Iconográfico (y XI) ¿Es la infografía un género periodístico? Revista Latina de Comunicación Social, 5(51).

Aguirre, C. R., Menjívar Valencia, E. y Morales, H. L. (2015). Elaboración de infografías: Hacia el desarrollo de competencias del siglo XXI. Diá-logos, (15), 23-27. https://doi.org/10.5377/ dialogos.v0i15.2207

Alyahya, D. (2019). Infographics as a learning tool in higher education: The design process and perception of an instructional designer. International Journal of Learning, Teaching and Educational Research, 18(1), 1-15. https://orcid.org/10.26803/ijlter.18.1.1

Best, J. W. y Kahn, J. V. (2006). Research in education (10.a ed.). Pearson.

Bicen, H. y Beheshti, M. (2017). The psychological impact of infographics in education. BRAIN. Broad Research in Artificial Intelligence and Neuroscience, 8(4), 99-108. https://www.edusoft. ro/brain/index.php/brain/article/view/733/821

Cassany, D., Luna, M. y Sanz, G. (2000). Enseñar lengua. Graó.

Creswell, J. W. (2012). Educational research. Planning, conducting, and evaluating quantitative and qualitative research (4. ${ }^{\mathrm{a}}$ ed.). Pearson.

Creswell, J. W. y Poth C. N. (2013). Qualitative inquiry and research design. Choosing among five approaches (3. ${ }^{\mathrm{a}} \mathrm{ed}$.). Sage.

Damyanov, I. y Tsankov, N. (2018). The role of infographics for the development of skills for cognitive modeling in education. IJET International Journal of Emerging Technologies in Learning, 13(1), 82-92. https://doi.org/10.3991/ijet.v13i01.7541

de Pablos, J. M. (1998). Siempre ha habido infografía. Revista Latina de Comunicación Social, 5, 1-5. https://studylib.es/doc/3006167/revista-latina-de-comunicaci\%C3\%B3n-socialsiempre-ha-habido-i...

Echevarría Martínez, M. A. y Gastón Barrenetxea, I. (2000). Dificultades de comprensión lectora en estudiantes universitarios. Implicaciones en el diseño de programas de intervención. Revista de Psicodidáctica, (10), 59-74. https://ojs.ehu.eus/index.php/psicodidactica/issue/view/31

García Madruga, J. J, Martín Cordero, J. I., Luque Vilaseca, J. L. y Santamaría Moreno, C. (1996). Comprensión y adquisición de conocimientos a partir de textos. Siglo Veintiuno.

Guzmán-Cedillo, Y., Lima-Villeda, N. y Ferreira-Rosa, S. (2015). An experience of elaborating didactic infographics on sexual diversity. Revista Latina de Comunicación Social, (70), 961981. https://orcid.org/10.4185/RLCS-2015-1080en

Hernández Sampieri, R., Fernández Collado, C. y Baptista Lucio, P. (2014). Metodología de la investigación (6. ${ }^{\mathrm{a}}$ ed.). McGraw-Hill. 
Leavy, P. (2017). Research design. Quantitative, qualitative, mixed methods, arts-based, and community-based participatory research approaches. The Guilford Press.

Maldonado Fuentes, A. C., Sandoval Rubilar, P. y Rodríguez Alveal, F. (2012). Comprensión lectora en la formación inicial docente: Estudiantes de educación general básica en una universidad del Consejo de Rectores. Folios, (35), 33-47. https://doi.org/10.17227/01234870.35folios33.47

Minervini, M. A. (2005). La infografía como recurso didáctico. Revista Latina de Comunicación Social, (59), 1-11. https://www.researchgate.net/publication/26527124_La infografia como recurso didactico

Muñoz García, E. (2014). Uso didáctico de las infografías. Espiral. Cuadernos del Profesorado, 7(14), 37-43. https://doi.org/10.25115/ecp.v7i14.969

Palmucci, D. (2017). Las infografías, nuevos espacios de lectura para el discurso científicopedagógico. Discurso \& Sociedad, 11(2), 262-288. http://www.dissoc.org/ediciones/v11n02/

Ponce, A., Rangone, C. y Funes, M. (2015). Relato de experiencia: Diseño de infografías como estrategia de enseñanza en Educación para la Salud en Ciencias Naturales y su didáctica en profesorados para la educación primaria de la provincia de Córdoba. VIII Jornadas Nacionales y $1^{\circ}$ Congreso Internacional sobre la Formación del Profesorado: Narración, Investigación y Reflexión sobre las Prácticas. Universidad Nacional de Mar del Plata. https://silo.tips/ download/palabras-clave-educacion-para-la-salud-innovaciones-en-el-aula-infografias

Reinhardt, N. (2010). Infografía didáctica: Producción interdisciplinaria de infografías didácticas para la diversidad cultural. Cuadernos del Centro de Estudios en Diseño y Comunicación. Ensayos, 11(31), 119-191. http://www.scielo.org.ar/pdf/ccedce/n31/n31a03.pdf

Rincón Carvajal, O. A. (2016). La infografía educativa como herramienta didáctica. Una posibilidad de mediación del proceso formativo en el área de Educación Física de los estudiantes del grado décimo y undécimo de la Institución Educativa Federico Ángel del municipio de Caldas -Antioquia- [Tesis de maestría]. Universidad Pontificia Bolivariana. https://repository.upb. edu.co/handle/20.500.11912/2780

Shabak Alrwele, N. (2017). Effects of infographics on student achievement and students' perceptions of the impacts of infographics. Journal of Education and Human Development, 6(3), 104-117. http://jehdnet.com/vol-6-no-3-september-2017-jehd

Solé, I. (1997). Estrategias de lectura. Graó.

Sudakov, I., Bellsky, T., Usenyuk-Kravchuk, S. y Polyakova, V. (2016). Infographics and mathematics: A mechanism for effective learning in the classroom. PRIMUS, 26(2), 158-167. https://doi.or $\mathrm{g} / 10.1080 / 10511970.2015 .1072607$ 
https://doi.org/10.15359/ree.26-1.23

https://www.revistas.una.ac.cr/index.php/educare

educare@una.ac.cr

\section{Apéndice A}

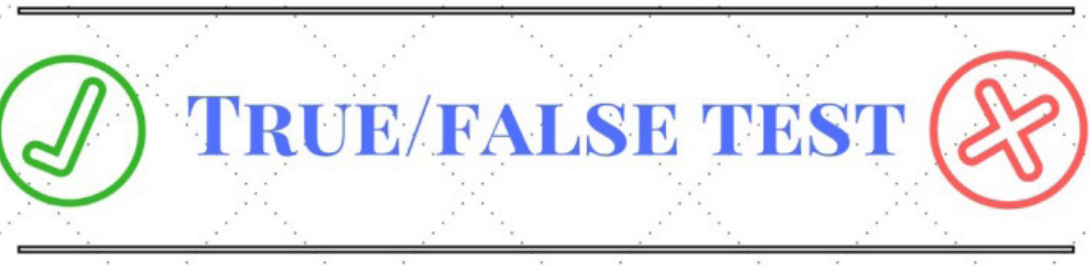

1 Avoid using more than one idea in a True or False question.

2 Keep the statement short and simple. The question should be based on the learner's knowledge.

3 True statements should be true under all circumstances. Avoid using may, seldom, possible, often, and other qualifiers.

4. Use negative statements sparingly and do not use double negatives. Negative words are often overlooked and should be underlined or in capital letters.

5 Opinion statements should be attributed to some source. The students should be aware of the opinions of the organization or individuals.
6 When cause and effect relationships are being measured; use only true propositions.

Avoid extraneous clues to the answer. For example, always, never, none, all, only, etc.

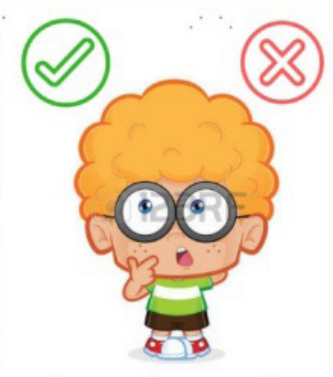

Lucero (șin fecha). Composing True/False Questions. Recuperado de: http://teaching.colostate.edu/tips/tip.cfm?tipid=155 

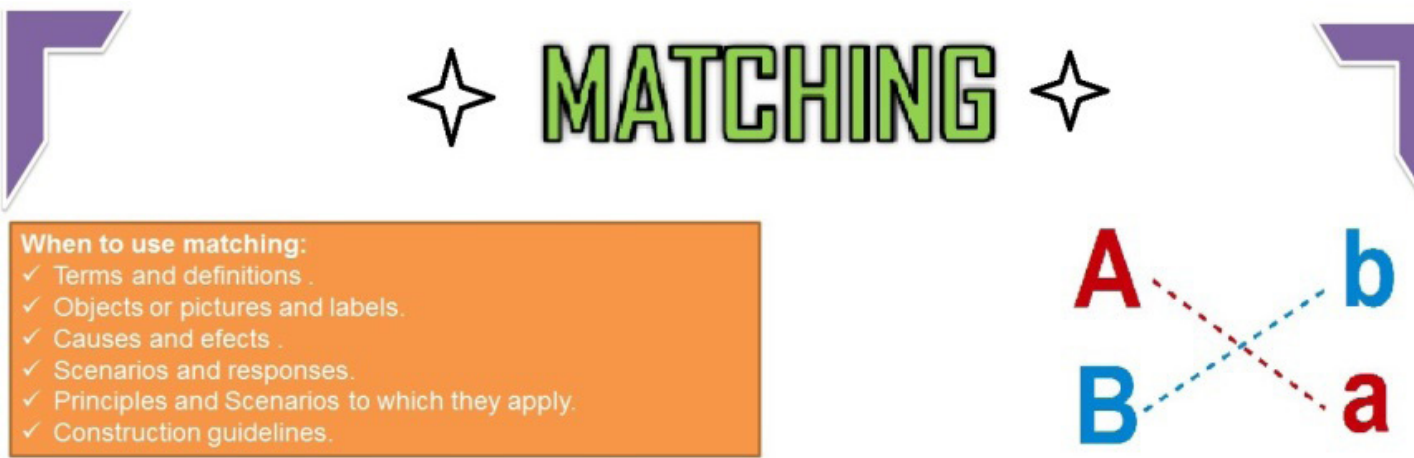

\section{Types of MATCHING}

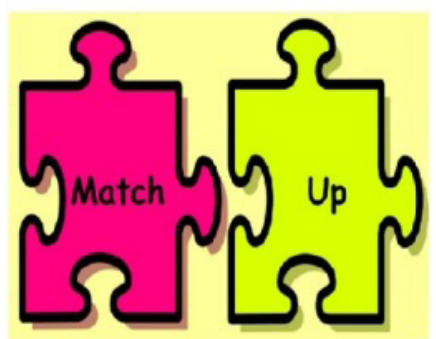

1.- Two-part directions.

2.-Parallel content.

3.-Plausible answers.

4.-Clueless.

5.-Unequal responses.

6. Limited premises.

7.-One correct anwer.

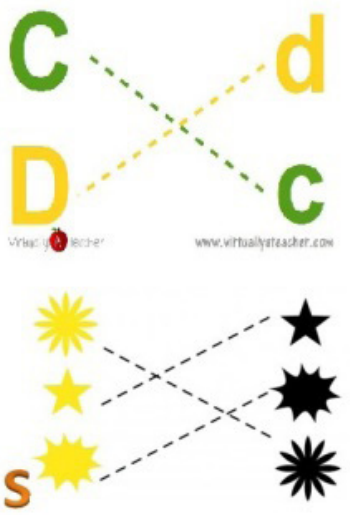
Advantages and Disadvantages.

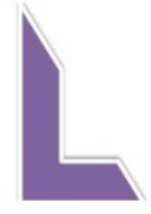

Team:

Laura Alicia Castillo Arenas

Jennifer Garcia Vázquez

Jairo de Jesús Gonzalez Martinez

\section{$\checkmark$ Advantages.}

\section{$\checkmark$ Drawbacks.}

Recuperado de : Malamed C.. (2010). Tips For Writing Matching Format Test Items. May 15, 2017, de The Elearner couch Sitio web:

itt://theelearningcoach.com/elearning_design/writing-matching-test-items/

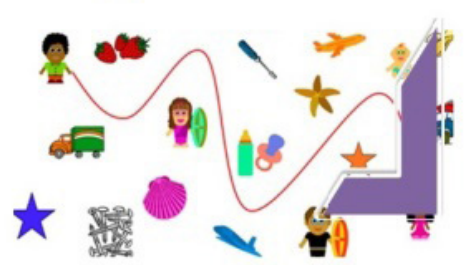


https://doi.org/10.15359/ree.26-1.23

https://www.revistas.una.ac.cr/index.php/educare

educare@una.ac.cr

\section{Apéndice B}

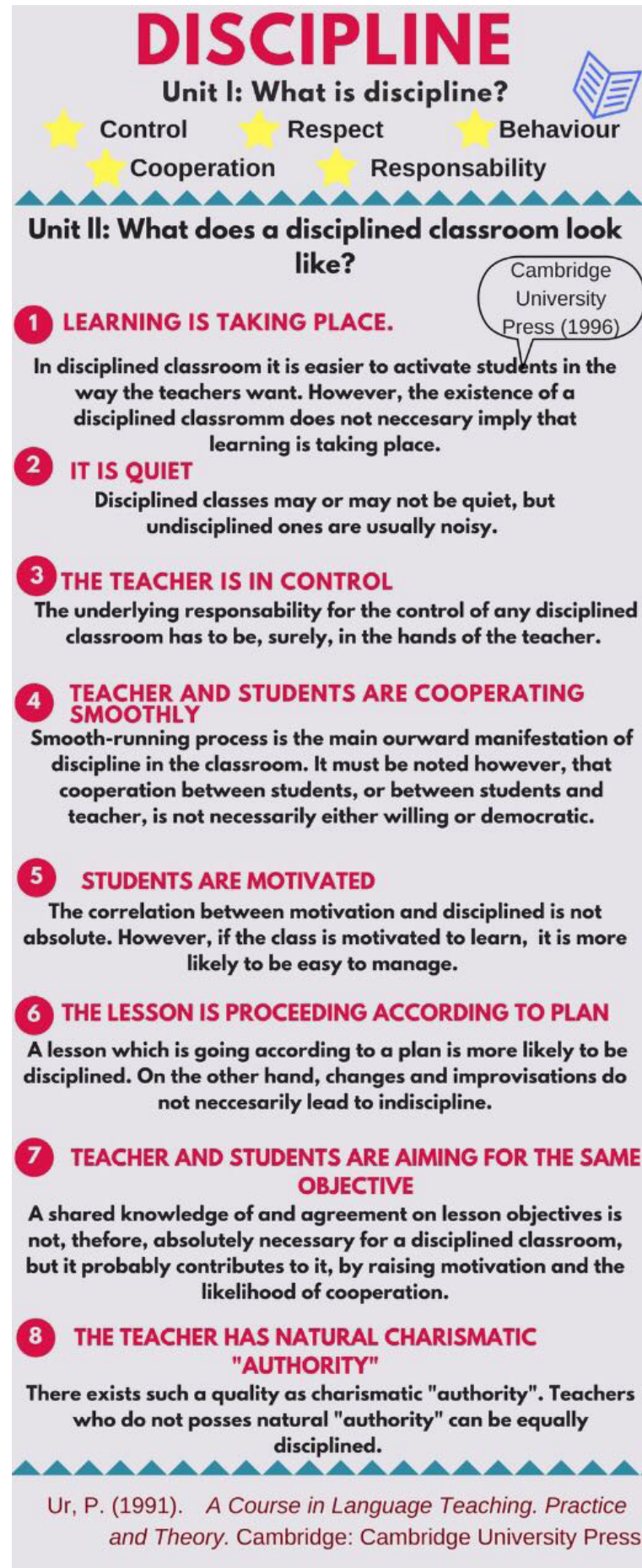


https://doi.org/10.15359/ree.26-1.23

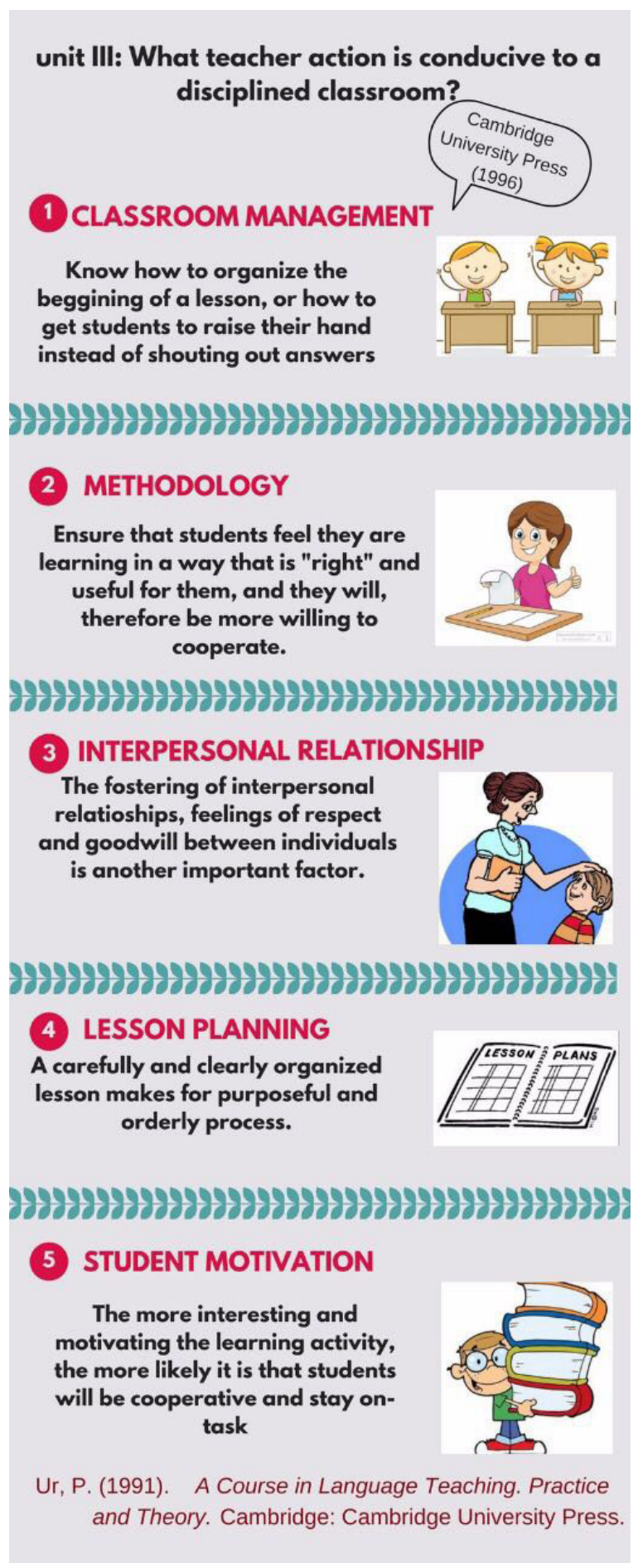

